ORIGINAL ARTICLE

\title{
The Effect of Psychological Well-being on Athletic Performance of Professional Athletes
}

\author{
TAYEBEH BANIASADI ${ }^{*}$, MIR HAMID SALEHIAN ${ }^{2}$ \\ ${ }^{1}$ Phd., Department of Kinesiology, Indiana University Bloomington, USA. \\ ${ }^{2}$ Phd., Department of Physical Education, Tabriz Branch, Islamic Azad University, Tabriz, Iran \\ "Corresponging author: tbaniasa@iu.edu
}

\begin{abstract}
The purpose of research was to study the effect of psychological well-being on the athletic performance of professional athletes. The present research was a descriptive of causal-comparative type. The statistical population consisted of professional skill level with an experience of 10 years $(n=100)$ were randomly selected. Data collection tools consisted of three questionnaires: Charbonneau exercise performance questionnaire (2001), Reif's psychological well-being questionnaire (1989). To test the hypotheses, multiple regression analysis was used. The findings showed that sporting performance of professional athletes with predictive psychological wellbeing is predictable. The effect of psychological well-being on the performance of athletes' professional sport is not significant.
\end{abstract}

Keywords: Psychological well-being, Professional athletes

\section{INTRODUCTION}

One of the basic variables in the field of sports performance is psychological well-being or mental health, which psychological well-being is defined as the development of real talents of each person. ${ }^{1}$ In recent years, a group of researchers in the field of mental health important from positive psychology, have chosen a different theoretical and research approach to explain and study this concept. They equated mental health with positive psychological functioning and conceptualized it in terms of the term "psychological well-being." This group does not consider the absence of disease to be sufficient for feeling healthy, but believes that having a sense of life satisfaction, sufficient progress, efficient and effective interaction with the world, positive energy and mood, good connection with society and positive progress are the characteristics of an individual. Is healthy. ${ }^{2}$

Mental health is an essential need for people at all times. One of the signs of mental health is the presence of internal empowering attributes or internal sources of power. Having these internal resources enables a person to continue his adaptive growth and maintain his mental health despite negative conditions. ${ }^{3}$ Welfare is defined in terms of quality and quantity of components according to which people find their lives enjoyable. In other words, how people value their lives is related to well-being. ${ }^{4}$ According to various studies, mental health is affected by various emotional, cognitive and personality aspects. ${ }^{5}$

Therefore, research related to health has also been developed with the development of psychological concepts and has added to the dimensions of health psychology. There is ample research evidence that unpleasant life events can affect and disrupt mental health and lead to mental health problems such as depression and anxiety. ${ }^{6}$

Salehian and Ghadiri ${ }^{7}$ showed that the athletic performance of professional athletes is predictable with psychological well-being.

Some research has shown that the use of maladaptive cognitive emotion regulation strategies is associated with mental health problems. ${ }^{8}$ In the present study, it is tried to predict the sports performance of professional athletes in terms of psychological well-being.
The questions that may arise for the researcher during the study are: What effect does psychological well-being have on the athletic performance of professional athletes?

\section{METHOD}

The present research is descriptive causal-comparative in terms of research method and applied in terms of purpose and survey in terms of data collection method.

Statistical Society: The statistical population of this study included professional female athletes in Tabriz in handball, footsall, basketball and volleyball, with an average age of 2062.6 and a history of 10 years (100 people) randomly selected.

Sample: Statistical sample of this study Due to the limited population, 100 professional athletes in Tabriz in handball, footsall, basketball and volleyball were selected as a sample.

\section{Research tools}

Charbonneau Sports Performance Questionnaire: This questionnaire was developed in 2001 by Charbonio. The questionnaire has five questions on the Likert scale and is designed to evaluate the performance of athletes and is completed by the relevant coach of each athlete. The scores obtained from the five questions show the final scores of the athlete's performance. This question is designed on a scale of 1 (very poor) to 5 (very excellent) (Charbonneau et al., 2001). The scores obtained from five questions are added together and the final score of the athlete's performance is obtained. This final score of the athlete's performance is in the range of 5 to 25 (minimum to maximum). The average reliability coefficients of this questionnaire were calculated and reported by Charbonio 0.71.

Psychological Welfare Questionnaire: This quesionaire was constructed by Raif (1989) and revised in 2002 (Husser et al., 2005). This scale measures the 6 factors of autonomy, mastery of the environment, personal growth, positive communication with others, purpose in life and selfacceptance, while the set of scores of these 6 factors is calculated as the overall score of psychological well-being. Also, the validity and reliability of psychological well-being scales have been reported in several appropriate studies. 
Direndock (2005) found the internal consistency of the subscales appropriate and Cronbach's alpha between 0.77 and 0.90. Cronbach's alpha method was used to determine the reliability of the questionnaire. The coefficients obtained for the psychological well-being questionnaire $(\alpha=0.69)$ were obtained.

Data collection method: The researcher studied and collected the basics related to psychological well-being in the form of a library and reviewed the existing articles and dissertations, and then the relevant questionnaires were prepared for the statistical population.
The researcher referred to the handball, footsall, basketball and volleyball sports delegations in coordination with the authorities and identified the professional athletes of the province in order to hold a coordination meeting and distribute questionnaires. Then, after collecting the questionnaires, the raw information was coded and the data were analyzed.

Statistical analysis methods: Multivariate linear regression analysis test was used to predict the effect of criterion variable on the predictor variable and FZT macro was used to find the magnitude of the effect with z-Fisher.

\section{RESULTS}

Table 1. Table of regression coefficients for the effect of psychological well-being components on athletic performance

\begin{tabular}{|l|l|l|l|l|l|}
\hline & \multicolumn{2}{|l|}{ Non-standardized coefficients } & Standardized coefficients & \multirow{2}{*}{ Sig. } \\
\cline { 2 - 5 } & $\mathrm{B}$ & \multicolumn{1}{|c|}{ Std dev. } & Beta & 2.650 & 0.006 \\
\hline Constant & 1.560 & 0.540 & & 0.801 & 0.410 \\
\hline Accept yourself & 0.109 & 0.139 & 0.095 & 0.541 & 0.572 \\
\hline Positive relationship with others & 0.078 & 0.145 & 0.0 .87 & 0.531 & 0.561 \\
\hline Autonomy & 0.089 & 0.151 & 0.071 & -0.799 & 0.389 \\
\hline Purposeful life & -0.148 & 0.186 & -0.120 & 3.625 & 0.001 \\
\hline Personal growth & 0.421 & 0.110 & 0.410 & -0.610 & 0.515 \\
\hline Mastery of the environment & -0.59 & 0.120 & -0.073 & & \\
\hline
\end{tabular}

As Table 1 shows, only the personal growth component has a significant positive effect on athletes' athletic performance $(p=0.001$ and $t=3.72)$.

Table 2. Correlation table and Watson-camera for the effect of psychological well-being on sports performance in professional athletes

\begin{tabular}{|l|l|l|l|l|l|}
\hline Skill level & $\begin{array}{l}\text { Multiple correlation } \\
\text { coefficient }\end{array}$ & $\begin{array}{l}\text { Determination } \\
\text { coefficient }\end{array}$ & Modified coefficient & $\begin{array}{l}\text { Determination } \\
\text { Standard error }\end{array}$ & $\begin{array}{l}\text { camera-Watson } \\
\text { estimation }\end{array}$ \\
\hline Professional athletes & 0.307 & 0.094 & 0.076 & 0.749 & 2.263 \\
\hline
\end{tabular}

As Table 2 shows, in professional athletes, psychological well-being has a significant positive effect on athletic performance. In professional athletes, the correlation coefficient is 0.31 and the determination coefficient is 0.09 .

\section{CONCLUSION}

The results showed that the athletic performance of professional athletes with psychological well-being is predictable. The results of this study are consistent with the results of research, BaniAsadi et al., ${ }^{9}$ BaniAsadi et al., ${ }^{10}$ Salehian \& Ghadiri, ${ }^{7}$ Dana et al., ${ }^{11}$ Mahdavi et al., ${ }^{12}$ Ghasempour and Judet. ${ }^{13}$ Research showing that this hypothesis is inconsistent has not been found in the background literature.

In explaining this issue, it can be stated that research shows that exercise and motor activities increase psychological well-being and reduce psychological problems. Physical health promotes the growth of mental health and the growth and development of cognitive wellbeing in individuals. Athletes are sociable and courageous people, so that in dealing with problems and issues have a higher tolerance threshold than their normal counterparts. Exercise and physical activity can strengthen and develop psychological well-being as one of the structures of positive psychology by increasing positive personality aspects and reducing inappropriate behaviors. In addition, athletes use exercise and physical activity as an effective coping method to deal with the worries and anxieties caused by everyday life, which in turn can increase psychological wellbeing as one of the Positive psychological structures help. Therefore, by strengthening psychological well-being, exercise allows athletes to better cope with stress and better cope with the challenges ahead.

\section{REFERENCES}

1. Dana, A, Rahimizadeh, F., Gozalzadeh, E., Eshgarf, S. (2018). Antidepressant Effects of Strength, Aerobic, and Combined Exercises among Adult Men, Journal of Rehabilation Medicine, 7(3): 199-207.

2. Karademas, E. (2007). Positive and negative aspects of well-being: Common and specific predictors. Personality and Individual Differences, 43: 277-287.

3. Haddadi Koesha, A.A., Roshan, R., Asgharnejad, Farid, A.A. (2016). Comparison of Emotional Intelligence and Mental Health of Students with their Emotional Relationships in Family. Journal of Psychology, Tabriz University, 1(4): 8769.

4. Diener, E. (2000). Subjective well- being: The science of happiness and a proposal for a national index. American psychologist, 55: 34-43.

5. Rajaei, A., Biazi, M. H., Habibipour, H. (2009). Basic religious beliefs of identity crisis and general youth health, Transformation Psychology, 6(22): 107-97.

6. Segerstrom, S. and Miller, G. (2014). Psychological strees and the human immune system: A metaanalytic study of 30 years of inquiry, Psychological Bulletin, 130: 610-630.

7. Salehian, M.H., Ghadiri, S. (2019). The Effect of Cognitive Emotion Regulation and Psychological Well-being on Athletic Performance of Professional and Semi-professional Athletes, Sports Psychology Studies, 8(29): 151-170. 
8. Garnefski N, Kraaij V, Spinhoven P, (2001). Negative life events, cognitive emotion regulation, and emotional problems, Personality and Individual Differences, 30(8): 1311-1327.

9. Baniasadi, T, NamaziZadeh M, Sheikh M. (2019). The Effects of BalanceTraining and Focus of Attention on Sway in Postural and Supra-Postural Tasks in the Elderly Population, Motor Behavior, 11 (36): 89-104.

10. Baniasadi T, Namazizadeh M, Sheikh M. Attentional Focus can affect Sway in Postural and Supra-postural Tasks in Community-Dwelling Older Adults. Ann Appl Sport Sci. 2018; $6(3): 31-37$.

11. Dana, A, Rafiee, S., Gholami, A. (2019). Motor reaction time and accuracy in patients with multiple sclerosis: effects of an active computerized training program, Neurological Sciences,

12. Mahdavi Nishiani, V., Ghale Nooy, F., Fazeli, F., Hashemi, S. S. (2016). Effectiveness of exercise on psychological wellbeing, quality of sleep and quality of life of students at Malayer National University, International Conference on Psychology and Education, Law and Social Sciences. (Persian)

13. Ghasempour, A., Joodat H. (2014). Comparison of psychological well-being among athletic and non-athletic students, Journal of Rafsanjan University of Medical Sciences, 3: 204-193. (Persian) 